\title{
EDITORIAL
}

\section{Toward an integration of family systems and developmental psychopathology approaches}

\author{
PATRICK T. DAVIES AND DANTE CICCHETTI \\ University of Rochester
}

Developmental psychopathology and family systems theory are distinct approaches that have flourished in relative isolation from each other. Contributing to their distinctiveness, important differences exist between the approaches in the primary unit of analysis. Whereas developmental psychopathology commonly focuses on individual development as the main unit of analysis, the whole family unit is the central object of study in family systems approaches. Accordingly, the primary objective of developmental psychopathology is to understand the nature, origins, and sequelae of individual patterns of adaptation and maladaptation over time (Cicchetti, 1993; Sroufe \& Rutter, 1984). In contrast, the principal goal in the family systems approach is to achieve a rich characterization of the interplay among relationships and individuals in the whole family unit, with a specific focus on identifying relationship structures, interpersonal boundaries, power distributions, and communication patterns (Cox \& Paley, 1997; Minuchin, 1985).

Work on this special issue was supported, in part, by a grant from the National Institute of Mental Health (MH 57318) awarded to Patrick Davies and grants from the National Institute of Mental Health (MH 45027-01 and MH 45027-06) and the Spunk Fund, Inc. awarded to Dante Cicchetti.

Address correspondence and reprint requests to: Patrick Davies, Department of Clinical and Social Sciences in Psychology, University of Rochester, Rochester, New York, 14627; E-mail: davies@psych.rochester.edu.
Differences in the substantive scope and goals between the two approaches are further instantiated in the establishment of distinct conceptual frameworks, assessment strategies, and data analytic models. At a conceptual level, developmental psychopathology contributes to an understanding of human development across the life span (Cicchetti, 1993; Cicchetti \& Toth, 1998; Rutter \& Sroufe, 2000); however, to date, empirical efforts to understand normal and abnormal development of individuals have focused predominantly on the first several decades of life (Cummings, Davies, \& Campbell, 2000; Wakefield, 1997). Conversely, because family systems theorists conceptualize the marital subsystem as the cornerstone of family functioning, a primary concern has been achieving an understanding of adult adaptation and maladaptation (Rossman, 1986). Furthermore, whereas a developmental psychopathology perspective requires consideration of broad developmental periods (e.g., months, years, or decades), family systems theorists are often more concerned with current family dynamics than the functioning of the family over relatively long periods of time (Rothbaum, Rosen, Ujie, \& Uchida, 2002).

At a methodological level, developmental psychopathology and family systems approaches also are rooted in different methods of justification. Family systems scholars commonly utilize case studies and qualitative meth- 
ods for testing hypotheses derived from conceptual models (e.g., Byng-Hall, 1999; Minuchin, 1985; Rothbaum et al., 2002). Parsimony achieved by limiting the sample size specifically allows for more thorough assessments of complex family dynamics. However, this approach constrains the analysis of the generalizability or specificity of findings across families. In contrast, developmental psychopathologists have commonly employed quantitative methods with relatively large samples to explicate the interindividual differences in developmental pathways (Richters, 1997; Sullivan, 1998). However, in the process, less attention has been devoted to capturing the rich complexity of the family system, a problem that is compounded by the limitations of many analytic tools in the quantitative paradigm (Richters, 1997).

Although developmental psychopathology and family systems perspectives can be distinguished from each other along theoretical, substantive, and methodological dimensions, the two approaches share common philosophical and theoretical roots (Cicchetti \& Aber, 1998; Combrinck-Graham, 1990; Minuchin, 1985; Sameroff, 1995). Guided by organic and contextual metaphors, both approaches have specifically embraced systems principles (Cicchetti \& Howes, 1991; Sroufe \& Fleeson, 1988). Units of analysis in developmental psychopathology (i.e., individual development) and family systems (i.e., the family unit) perspectives are regarded as operating within open systems. In open systems, functioning is conceptualized as an ongoing transactional interplay between an active changing organism in a dynamic changing context (Cicchetti, 1993; Cicchetti \& Tucker, 1994; Granic \& Hollenstein, 2003; S. Minuchin \& Fishman, 1981). Given the interdependency among components in an open system, holism is accepted as a basic principle in each approach. Thus, rather than attempting to understand the unit of analysis by dissecting the system into a series of parts, holism dictates that any part of the whole gains meaning and purpose from the other parts and, therefore, must be examined in the fabric of the whole system (Santostefano \& Baker, 1972; Werner \& Kaplan, 1963). For example, the organizational perspective in developmen- tal psychopathology suggests that the adaptive and maladaptive value of any single dimension of child functioning cannot be fully understood without evaluating its meaning and function in the larger context of children's response processes and adjustment over time (Cicchetti \& Howes, 1991; Davies \& Forman, 2002). Likewise, family systems theory emphasizes that an overt manifestation of relationship functioning (e.g., warmth) may have multiple meanings (e.g., healthy relationship, efforts to compensate for adversity in the family system, or maladaptive coalition formation) depending on how it operates in the larger family system (Byng-Hall, 2002; Davies, 2002; Erel \& Burman, 1995).

The multitude of dynamic organismenvironment transactions comprising open systems is further conceptualized to result in a plurality of pathways of adaptation and maladaptation for individuals and families. Consequently, models of adaptation in developmental psychopathology and family systems are not restricted to accepting the notion that one cause can only have one outcome. Rather, each approach embraces the concept of equifinality, which is reflected in the notion that multiple causes and processes can result in one outcome, and the concept of multifinality, which is reflected in the assumption that multiple outcomes can originate from a single factor or mechanism (Cicchetti, 1990; Cicchetti \& Rogosch, 1996; Nichols, 1999; Sroufe, 1989). For example, equifinality in developmental psychopathology is reflected in the assumption that organic (e.g., specific neuropsychological impairments), family (e.g., enmeshed parent-child relations), and contextual (e.g., atmosphere of school classroom) factors assume different roles and functions across individuals in the emergence or maintenance of a common disturbance (e.g., attentiondeficit disorder; Sroufe, 1997). Likewise, equifinality in family systems theory is evidenced by clinical observations indicating that children can thrive in the context of many different patterns of family functioning, including family units experiencing significant psychopathology (Nichols, 1999).

Change in organism-context transactions is also expected to assume an orderly form 
through successive hierarchical integration of systems. Thus, guided by the orthogenetic principle (Werner, 1948), developmental psychopathology has commonly characterized individual adaptation over time in terms of the continual hierarchical integration of psychological systems into new increasingly complex and differentiated forms of functioning (Cicchetti \& Schneider-Rosen, 1986). For example, the development of emotion regulation has been conceptualized as a series of qualitative and quantitative changes based on the differentiation, specialization, and integration of neuropsychological, cognitive, linguistic, and psychosocial processes (e.g., Kopp, 1989; Thompson, Flood, \& Lundquist, 1995). Similarly, in family systems theory, the organization of the family system is characterized by hierarchical transformations emerging from transactional feedback loops involving the biopsychosocial characteristics of family members, structural processes in the family (e.g., relationship boundaries; power distribution; role clarity), and perturbations operating in the open system (Cox \& Paley, 1997; Gilbert \& Christensen, 1988; Kerr, 2003).

The theoretical compatibility of developmental psychopathology and family systems perspectives raises several significant questions. Can we integrate these two approaches in mutually enriching ways? In expanding the boundaries of the family systems perspective, is it possible to complement the aim of achieving a rich understanding of complex family dynamics by examining its implications for understanding patterns of adjustment and maladjustment of individual family members (Combrinck-Graham, 1990; Evans, 1978; Rothbaum et al., 2002; Wachtel, 1987)? Likewise, in challenging the conventional boundaries of developmental psychopathology, is it possible to examine individual patterns of adjustment and maladjustment in the context of richer, systems conceptualizations of family process (Cicchetti \& Howes, 1991; Davies, 2002; Minuchin, 2002)? With recent advances in systems theory, methodological tools, and analytic models, we believe that the time is ripe for ceasing opportunities to merge family systems and developmental psychopathology perspectives in innovative and exciting ways.
Therefore, the principal objective of this Special Issue of Development and Psychopathol$o g y$ is to provide exemplars of the value, potential, and challenges of integrating these two approaches.

To achieve this goal, we invited contributors of this Special Issue to formulate conceptual models, research questions, and methodological designs that address issues and problems at the interface of developmental psychopathology and family systems perspectives. Because theoretical progress has continued to outpace methodological and analytic advances in family systems and developmental psychopathology, achieving fidelity between the conceptual models inspired by the integration of these two perspectives and the methodological and analytic tools used to address research questions is a particularly formidable challenge. To directly address the gap between theoretical and empirical progress, we solicited substantially more empirical papers than theoretical papers for this Special Issue. Specific contributions address a wide array of issues. A prevailing theme of many of the papers involves the identification of the biopsychosocial antecedents, correlates, and sequelae of different configurations of relationship quality and boundaries in the family system across a broad portion of the life span (e.g., infancy to adulthood). Another prominent focus of the contributions is on understanding the role that parental and child psychopathology play in the context of family system processes. Still another common goal of papers is to elucidate the multiplicity of pathways between forms of family adversity, system conceptualizations of family relationship quality (e.g., alliances; boundary disturbances), and child adaptation and maladaptation.

In an effort to close the gap between theoretical and methodological developments, the contributors regularly strive to develop, refine, and employ creative methods for assessing family systems constructs. Thus, the Special Issue contains innovative questionnaire, interview, and observational methods for capturing a wide array of family systems concepts, including alliance and boundary formation across family relationships, coparenting relationship quality, whole family functioning, 
power and hierarchy dynamics in the family, and adult and child representations of familylevel processes. The contributions further illustrate the diversity of analytic tools available for addressing family systems questions and issues, including pattern-based approaches (e.g., cluster analysis), multivariate variable-based approaches (e.g., mediator and moderator models; complex blends of mediator and moderator models), and contextually rich qualitative and descriptive analyses. The cumulative result is the expansion of methodological strategies and analytic tools for the research armamentarium of developmental psychopathologists.

In closing, developmental psychopathology has a unique tradition of remaining flexible, inclusive, integrative, and permeable in its boundaries, especially in its relationship with other disciplines and approaches (Cicchetti \& Sroufe, 2000). In this context, it is surprising that little progress has been made in expanding the boundaries of developmental psychopathology to incorporate family systems themes, especially in light of the theoretical compatibility of the two approaches (for exceptions, see Howes, Cicchetti, Toth, \& Rogosch, 2000; McHale \& Rasmussen, 1998; O'Connor, Hetherington, \& Reiss, 1998). The purpose of this Special Issue is to draw atten-

\section{References}

Byng-Hall, J. (1999). Family and couple therapy: Toward greater security. In J. Cassidy \& P. R. Shaver (Eds.), Handbook of attachment: Theory, research and clinical applications (pp. 625-645). New York: Guilford Press.

Byng-Hall, J. (2002). Relieving parentified children's burdens in families with insecure attachment patterns. Family Process, 41, 375-388.

Cicchetti, D. (1990). A historical perspective on the discipline of developmental psychopathology. In J. Rolf, A. Masten, D. Cicchetti, K. Nuechterlein, \& S. Weintraub (Eds.), Risk and protective factors in the development of psychopathology (pp. 2-28). New York: Cambridge University Press.

Cicchetti, D. (1993). Developmental psychopathology: Reactions, reflections, projections. Developmental Review, 13, 471-502.

Cicchetti, D., \& Aber, J. L. (1998). Contextualism and developmental psychopathology. Development and Psychopathology, 10, 137-142.

Cicchetti, D., \& Howes, P. W. (1991). Developmental psychopathology in the context of the family: Illustrations from the study of child maltreatment. Canadian Journal of Behavioural Science, 23, 257-281.

Cicchetti, D., \& Rogosch, F. A. (1996). Equifinality and tion to potential advances in knowledge gained even in the initial stages of merging family systems and developmental psychopathology approaches. Given the early stage of these integrative efforts, we also hope this set of papers prompts discerning readers to identify additional directions for future research in this area. For example, to further increase the fidelity between these investigations and principles of developmental psychopathology, recent advances in growth curve analysis will be valuable tools for delineating the interplay between family systems processes and individual differences in developmental trajectories of psychological adjustment (e.g., Curran \& Willoughby, 2003; Shaw, Gilliom, Ingoldsby, \& Nagin, 2003). Likewise, new techniques for integrating qualitative and quantitative research hold considerable promise for overcoming differences between developmental psychopathology and family systems approaches in the use of methodological paradigms (e.g., Korbin, Coulton, Chard, Platt-Houston, \& Su, 1998; Sullivan, 1998). We invite you to use the foundation provided in this Special Issue to further the integration between developmental psychopathology and family systems approaches. The resulting synergy holds great promise for enhancing work in both areas.

multifinality in developmental psychopathology. Development and Psychopathology, 8, 597-600.

Cicchetti, D., \& Schneider-Rosen, K. (1986). An organizational approach to childhood depression. In M. Rutter, C. Izard, \& P. Read (Eds.), Depression in young people: Clinical and developmental perspectives ( $\mathrm{pp}$. 71-134). New York: Guilford Press.

Cicchetti, D., \& Sroufe, L. A. (2000). The past as prologue to the future: The times, they've been a-changin'. Development and Psychopathology, 12, 255-264.

Cicchetti, D., \& Toth, S. L. (1998). Perspectives on research and practice in developmental psychopathology. In W. Damon (Ed.), Handbook of child psychology (5th ed., Vol. 4, pp. 479-583). New York: Wiley.

Cicchetti, D., \& Tucker, D. (1994). Development and selfregulatory structures of the mind. Development and Psychopathology, 6, 533-549.

Combrinck-Graham, L. (1990). Developments in family systems theory and research. Journal of the American Academy of Child and Adolescent Psychiatry, 29, 501-512.

Cox, M. J., \& Paley, B. (1997). Families as systems. Annual Review of Psychology, 48, 243-267.

Cummings, E. M., Davies, P. T., \& Campbell, S. B. (2000). Developmental psychopathology and family process: 
Theory, research, and clinical implications. New York: Guilford Press.

Curran, P. J., \& Willoughby, M. T. (2003). Implications of latent trajectory models for the study of developmental psychopathology. Development and Psychopathology, 15, 581-612.

Davies, P. T. (2002). Conceptual links between ByngHall's theory of parentification and the emotional security hypothesis. Family Process, 41, 551-555.

Davies, P. T., \& Forman, E. M. (2002). Children's patterns of preserving emotional security in the interparental subsystem. Child Development, 73, 1880-1903.

Erel, O., \& Burman, B. (1995). Interrelatedness of marital relations and parent-child relations: A metaanalytic review. Psychological Bulletin, 118, 108-132.

Evans, R. C. (1978). Comment on Heard's "A case study of structural family therapy." Family Process, 17, 338-353.

Gilbert, R. K., \& Christensen, A. (1988). The assessment of family alliances. Advances in Behavioral Assessment of Children and Families, 4, 219-252.

Granic, I., \& Hollenstein, T. (2003). Dynamic systems methods for models of developmental psychopathology. Development and Psychopathology, 15, 641-669.

Howes, P. W., Cicchetti, D., Toth, S. L., \& Rogosch, F. A. (2000). Affective, organizational, and relational characteristics of maltreating families: A systems perspective. Journal of Family Psychology, 14, 95-110.

Kerr, M. (2003). Multigenerational family systems theory of Bowen and its application. In G. P. Sholevar (Ed.), Textbook of family and couples therapy: Clinical applications (pp. 103-126). Washington, DC: American Psychiatric Publishing.

Kopp, C. B. (1989). Regulation of distress and negative emotions: A developmental view. Developmental Psychology, 25, 343-354.

Korbin, J., Coulton, C. J., Chard, S., Platt-Houston, C., \& $\mathrm{Su}, \mathrm{M}$. (1998). Impoverishment and child maltreatment in African American and European American neighborhoods. Development and Psychopathology, 10, 215-233.

McHale, J. P., \& Rasmussen, J. L. (1998). Co-parental and family group-level dynamics during infancy: Early family precursors of child and family functioning during preschool. Development and Psychopathology, 10, 39-59.

Minuchin, P. (1985). Families and individual development: Provocations from the field of family therapy. Child Development, 56, 289-302.

Minuchin, P. (2002). Cross-cultural perspectives: Implications for attachment theory and family therapy. Family Process, 41, 546-550.

Minuchin, S., \& Fishman, H. C. (1981). Family therapy techniques. Cambridge, MA: Harvard University Press.

Nichols, W. C. (1999). Family systems therapy. In R. S. Walker \& T. H. Ollendick (Eds.), Handbook of psychotherapies with children and families (pp. 137151). Dordrecht: Kluwer.

O’Connor, T. G., Hetherington, E. M., \& Reiss, D. (1998). Family systems and adolescent development: Shared and nonshared risk and protective factors in nondivorced and remarried families. Development and Psychopathology, 10, 353-375.

Richters, J. E. (1997). The Hubble hypothesis and the developmentalist's dilemma. Development and Psychopathology, 9, 193-229.

Rossman, B. L. (1986). Developmental perspectives in family therapy with children. In H. C. Fishman \& B. L. Rossman (Eds.), Evolving models for family change: A volume in honor of Salvador Minuchin (pp. 227-233). New York: Guilford Press.

Rothbaum, F., Rosen, K., Ujie, T., \& Uchida, N. (2002) Family systems theory, attachment theory, and culture. Family Process, 41, 328-350.

Rutter, M., \& Sroufe, L. A. (2000). Developmental psychopathology: Concepts and challenges. Development and Psychopathology, 12, 265-296.

Sameroff, A. J. (1995). General systems theories and developmental psychopathology. In D. Cicchetti \& D. J. Cohen (Eds.), Developmental psychopathology: Vol 1. Theory and methods (pp. 659-695). New York: Wiley.

Santostefano, S., \& Baker, A. H. (1972). The contribution of developmental psychology. In B. Wolman (Ed.), Manual of child psychopathology (pp. 1113-1153). New York: McGraw-Hill.

Shaw, G. S., Gilliom, M., Ingoldsby, E. M., \& Nagin, D. S. (2003). Trajectories leading to school-age conduct problems. Developmental Psychology, 39, 189-200.

Sroufe, L. A. (1989). Pathways to adaptation and maladaptation: Psychopathology as developmental deviation. In D. Cicchetti (Ed.), Rochester symposium on developmental psychopathology: The emergence of a discipline (Vol. 1, pp. 13-40). Hillsdale, NJ: Erlbaum.

Sroufe, L. A. (1997). Psychopathology as an outcome of development. Development and Psychopathology, 9 , 251-268.

Sroufe, L. A., \& Fleeson, J. (1988). The coherence of family relationships. In R. A. Hinde \& J. StevensonHinde (Eds.), Relationships within families: Mutual influences (pp. 27-47). Oxford: Oxford University Press.

Sroufe, L. A., \& Rutter, M. (1984). The domain of developmental psychopathology. Child Development, 56 , 316-325.

Sullivan, M. L. (1998). Integrating qualitative and quantitative methods in the study of developmental psychopathology in context. Development and Psychopathology, 10, 377-393.

Thompson, R. A., Flood, M. F., \& Lundquist, L. (1995). Emotion regulation: Its relations to attachment and developmental psychopathology. In D. Cicchetti \& S. L. Toth (Eds.), Rochester Symposium on Developmental Psychopathology: Vol. 6. Emotion, cognition, and representation (pp. 261-299). Rochester, NY: University of Rochester Press.

Wachtel, E. F. (1987). Family systems and the individual child. Journal of Marital and Family Therapy, 13 , $15-25$.

Wakefield, J. (1997). When is development disordered? Developmental psychopathology and the harmful dysfunction analysis of mental disorder. Development and Psychopathology, 9, 269-290.

Werner, H. (1948). Comparative psychology of mental development. New York: International Universities Press.

Werner, H., \& Kaplan, B. (1963). Symbol formation. New York: Wiley. 